\title{
The Impact of Isolation Due to COVID-19 on Physical Activity Levels in Adult Students
}

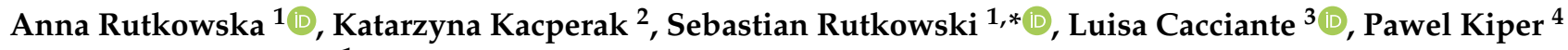 \\ and Jan Szczegielniak ${ }^{1}$ \\ 1 Faculty of Physical Education and Physiotherapy, Opole University of Technology, 45-758 Opole, Poland; \\ a.rutkowska@po.edu.pl (A.R.); j.szczegielniak@po.edu.pl (J.S.) \\ 2 Descartes' Error Student Research Association, Faculty of Physical Education and Physiotherapy, \\ Opole University of Technology, 45-758 Opole, Poland; katarzyna.kacperak@gmail.com \\ 3 Laboratory of Rehabilitation Technologies, Ospedale San Camillo IRCCS, 30126 Venice, Italy; \\ luisa.cacciante@ospedalesancamillo.net \\ 4 Physical Medicine and Rehabilitation Unit, Azienda ULSS 3 Serenissima, 30126 Venice, Italy; \\ pawelkiper@hotmail.com \\ * Correspondence: s.rutkowski@po.edu.pl; Tel.: +48-507-027-792
}

Citation: Rutkowska, A.; Kacperak,

K.; Rutkowski, S.; Cacciante, L.; Kiper, P.; Szczegielniak, J. The Impact of Isolation Due to COVID-19 on Physical Activity Levels in Adult Students. Sustainability 2021, 13, 446. https://doi.org/10.3390/su13020446

Received: 16 November 2020

Accepted: 3 January 2021

Published: 6 January 2021

Publisher's Note: MDPI stays neutral with regard to jurisdictional clai$\mathrm{ms}$ in published maps and institutional affiliations.

Copyright: (C) 2021 by the authors. Licensee MDPI, Basel, Switzerland. This article is an open access article distributed under the terms and conditions of the Creative Commons Attribution (CC BY) license (https:// creativecommons.org/licenses/by/ $4.0 /)$.
Abstract: The lockdown with a prohibition of free mobility introduced in many countries has affected restrictions in physical activity (PA). The purpose of the study was to compare PA during restrictions and the "unfreezing" stage. The study group consisted of 89 healthy adult students. To assess the level of PA, a long version of the International Physical Activity Questionnaire (IPAQ) was used. The first evaluation was carried out in the period from 16 to 20 April 2020 at the time of the lockdown and the second in the period from 11 to 14 May 2020 during the so-called "unfreezing". The average total PA rate during the first measurement was 8640 metabolic equivalent (MET)-min/week and in the second, 10,560 MET-min/week. The analysis of total energy expenditure showed a statistically significant difference $(p<0.029)$. The establishment of "unfreezing" laws for sport and recreation and the reduction of restrictions have significantly contributed to an increase in the overall level of PA. Based on our outcomes, we recommend students follow the scientific guidelines for undertaking PA (i.e., $\mathrm{WHO}$ ) during the pandemic in order to maintain an appropriate pro-healthy dose of exercise.

Keywords: COVID-19; physical activity; International Physical Activity Questionnaire (IPAQ); energy expenditure

\section{Introduction}

The coronavirus (COVID-19) may cause severe respiratory syndrome (SARS-CoV-2) and appeared for the first time in Wuhan, Hubei Province, China in early December 2019. On 31 December, an outbreak of atypical pneumonia was announced in Wuhan [1,2]. Clinical symptoms of patients with COVID-19 include fever, sore throat, coughing, fatigue, or gastrointestinal infections, which can appear in a smaller population of patients. In more severe cases, respiratory failure symptoms, as well as heart and kidney damage, may occur. This can happen especially in the elderly and in people with other chronic diseases coexisting [3]. The virus spreads mainly through the respiratory tract, through the drops arising from coughing, sneezing, and talking, and through contaminated surfaces and biological substances [4].

The COVID-19 infection has spread rapidly to other countries around the world, triggering the reaction of the World Health Organization (WHO), which on 11 March 2020 declared the pandemic status. In Poland, the first case of COVID-19 infection was diagnosed on 4 March 2020. In the period from 14 to 20 March, Poland had a state of epidemic and danger. From 15 March, a sanitary cordon was introduced on the Polish borders, significantly limiting border traffic. Since $20 \mathrm{March}$, according to a regulation of the former Minister of Health, an epidemic law was imposed in Poland. Temporary 
physical isolation precautions were taken to stop the spread of the virus and to prevent overloading health care systems. Since 12 March, all educational institutions were closed. The introduced restrictions have presented large-scale challenges for traditional or faceto-face education [5]. Thus, many new techniques and forms of education, likewise technological solutions, were introduced [6,7]. The period from 25 March to 20 April was defined as a lockdown. A similar trend, depending on the number of infections, was observed worldwide.

The restrictions imposed were a major barrier for physical activity maintenance. However, these restrictions (e.g., closure of parks, boulevards, state forests, or beaches) were introduced to manage the spread of infection. A review of the literature showed that quarantine combined with other preventive methods such as social distancing, school closures, and reduced travel opportunities can reduce the number of infections and deaths due to COVID-19 [8]. However, studies also indicate that even short restrictions on physical activity (PA) have a negative impact on health. Literature showed that 14 days of reduced PA contributes to: fat accumulation, hyperinsulinemia, reduced cardiopulmonary capacity, lower limb muscle atrophy, negative changes in glucose and insulin metabolism, impairment of skeletal muscle protein synthesis, loss of muscle mass, as well as an increase in inflammatory cytokines [9]. Long-term physical inactivity may result in hypertension, obesity, and ischemic heart disease [10]. Passive leisure also predisposes a decrease in metabolism and physical performance, as well as the deterioration of functionality in everyday life and quality of life. Another issue that needs to be addressed is the major involvement in eLearning that contributes additionally to a sedentary lifestyle. It has been proven that higher fitness levels are associated with higher grades when compared to those with lower fitness levels [11]. It is worth noting that the traditional form of education can force students to move throughout the day, transitioning between classes and activities. On the other hand, eLearning requires screen usage, which contributes to seated time. Thus, incorporating and encouraging movement through remote teaching should be considered as common practice. However, this would be no small undertaking, while researchers have specified difficulties in providing online physical education classes [12]. Among the most frequently indicated difficulties is the monotony associated with limited environmental conditions and educational content, which ultimately reduced the effectiveness of transferring the values of physical education to students. To date, no comprehensive guidelines or programs with the aim to educate students on how to become active during restrictions exist.

Thus, with the scarcity of literature related to the evaluation of the PA level of Polish adult students during the lockdown, we designed this trial with the aim to compare PA during restrictions and the "unfreezing" stage. Therefore, we hypothesized that the establishment of "unfreezing" laws for sport and recreation will contribute to an increase in the overall level of physical activity.

\section{Materials and Methods}

\subsection{Participants}

The level of PA during and after the country lockdown was assessed through the International Physical Activity Questionnaire (IPAQ). Eighty-nine young adult students were enrolled with sociodemographic characteristics as presented in Table 1. Students represented a total of 11 Polish universities among 17 different fields of study in technical, medical, and humanities disciplines. Students took part in the study voluntarily. Information about the study was provided through social media. The exclusion criteria comprised diseases and injuries of the musculoskeletal system impairing locomotion function that would preclude active participation in the study and testing. All participants agreed to participate in the study and informed consent was written from all of the subjects. The long version of the International Physical Activity Questionnaire approved by the International Committee of IPAQ was used [13]. The first evaluation was carried out in the period from 16 to 20 April 2020 i.e., during the lockdown. The second assessment was performed in 
the period from 11 to 14 May 2020 during the so-called "unfreezing" stage. The respondents answered the questionnaire on-line.

Table 1. Sociodemographic characteristics of the group.

\begin{tabular}{cc}
\hline Variable & \\
\hline Age (years), mean (SD) & $23.39(1.5)$ \\
Female, n (\%) & $58(65.2 \%)$ \\
BMI, mean (SD) & $22.6(3.4)$ \\
Underweight & $5(5.6 \%)$ \\
Normal weight & $67(75.3)$ \\
Overweight & $17(19.1)$ \\
Urban residence, $\mathrm{n}(\%)$ & $41(46.1 \%)$ \\
Employed, $\mathrm{n}(\%)$ & $28(31.5 \%)$ \\
\hline
\end{tabular}

BMI: body mass index; SD: standard deviation.

\subsection{Outcome Measure}

The full IPAQ consists of 27 questions divided into five parts: professional work, mobility, homework, sport and recreation, and sitting time. The first includes questions relating to PA devoted to professional work, agriculture, and other social work outside the home. The next part covers the time of traveling to work, shopping, entertainment, in the form of walking, or by means of transport such as car, bicycle, and public transport. The third part includes questions about the time spent on certain types of cleaning activities, housework, and family care. The next part enables the estimation of the time of PA as recreation, sport, or leisure. The last part contains questions about the time spent sitting during work, leisure, and study. This could be, for example, sitting at a desk, watching $\mathrm{TV}$, or reading. The questionnaire takes into account the activity performed during the last 7 days, which lasts at least $10 \mathrm{~min}$ at a time. The full IPAQ version was used in this study in order to precisely characterize the activity level, as opposed to the short version, which consists of only 7 questions.

\subsection{Scoring Protocol}

On the basis of the protocol developed by the International IPAQ Committee [13], the PA level was converted into a metabolic equivalent (MET), which is equivalent to the resting metabolic rate and corresponding to $3.5 \mathrm{~mL} \mathrm{O}_{2} \mathrm{~kg}^{-1} \mathrm{~min}^{-1}$ or $1 \mathrm{kcal} \mathrm{kg}^{-1} \mathrm{~h}^{-1}$. We enumerate the weekly PA level, expressed as energy expenditure in MET-minutes/week (MET-min/wk). The energy expenses for the various activities during the week were calculated into a MET-min/week unit by multiplying the coefficient for a given activity by the number of days of activity per week and duration in minutes. Coefficients for all activity types were as follows: 8.0 for vigorous-intensity physical activities; 6.0 for cycling; 4.0 for moderate-intensity physical activities; and 3.3 for walking. The total PA per week was calculated by adding up the obtained MET-min/week values for all activities [14]. The total sitting time was also calculated based on the formula: sitting time on a weekday $\times 5+$ sitting time at the weekend $\times 2+$ sitting time in means of transport. Based on the collected data, the respondents were classified into groups of PA levels. The qualification to the individual categories was based on the protocol developed by the International IPAQ Committee. Three levels of PA are presented in Table 2. 
Table 2. The International IPAQ Committee qualification of PA levels.

\begin{tabular}{|c|c|c|}
\hline High & Moderate & Low \\
\hline $\begin{array}{l}\text { (a) vigorous-intensity activity } \\
\text { on at least } 3 \text { days achieving a } \\
\text { minimum of at least } 1500 \\
\text { MET-min/week OR } \\
\text { (b) } 7 \text { or more days of any } \\
\text { combination of walking, } \\
\text { moderate-intensity or } \\
\text { vigorous intensity activities } \\
\text { achieving a minimum of at } \\
\text { least } 3000 \text { MET-min/week }\end{array}$ & $\begin{array}{l}\text { (a) } 3 \text { or more days of vigorous } \\
\text { activity of at least } 20 \text { min per } \\
\text { day OR } \\
\text { (b) } 5 \text { or more days of } \\
\text { moderate-intensity activity or } \\
\text { walking of at least } 30 \text { min per } \\
\text { day OR } \\
\text { (c) } 5 \text { or more days of any } \\
\text { combination of walking, } \\
\text { moderate-intensity or } \\
\text { vigorous intensity activities } \\
\text { achieving a minimum of at } \\
\text { least } 600 \text { MET-min/week }\end{array}$ & $\begin{array}{l}\text { This is the lowest level of } \\
\text { physical activity. Those } \\
\text { individuals who not meet } \\
\text { criteria for Categories } 2 \text { or } 3 \\
\text { are considered } \\
\text { "insufficiently active" }\end{array}$ \\
\hline
\end{tabular}

MET; metabolic equivalent.

\subsection{Statistical Methods}

All statistical analyses were performed using the software Statistica 13 (StatSoft, Cracow, Poland). The statistical significance level was set at $\alpha=0.05$. The normality distribution was verified with the Shapiro-Wilk test. Non-parametric tests were used. Continuous variables were presented as mean \pm standard deviation (SD). To compare the differences in the level of PA the Kruskal-Wallis one-way analysis of variance was used, and Spearman's Rank was used to assess the correlation.

\section{Results}

\subsection{Energy Expenditure}

The average total PA rate among all surveyed students during the first measurement was $8640 \mathrm{MET}$-min/week, and this value was higher in men (9065 MET-min/week) than in women (8412 MET-min/week). The second measurement, performed during the period of "unfreezing" of sport and recreation, was characterized by significantly higher PA rates. The average energy expenditure amounted to 10,560 MET-min/week (Table 3). The analysis of the value of total energy expenditure for all participants showed a statistically significant difference between the lockdown and "unfreezing" periods $(p<0.029)$.

Table 3. Total weekly energy expenditure.

\begin{tabular}{cccccccc}
\hline \multirow{2}{*}{ Variable } & \multicolumn{4}{c}{ Lockdown } & \multicolumn{3}{c}{ “Unfreezing” } \\
\cline { 2 - 8 } & Mean & SD & Range & Mean & SD & Range & $p$ \\
\hline Job-related & 2289 & 6044 & 31,998 & 3273 & 6597 & 36,192 & 0.048 \\
Transportation & 1220 & 1969 & 12,474 & 1622 & 1555 & 5724 & 0.001 \\
House maintenance & 3023 & 3751 & 18,780 & 2941 & 4029 & 23,520 & 0.904 \\
Recreation, sport & 2108 & 2067 & 9198 & 2724 & 3138 & 8258 & 0.116 \\
\hline Total PA & 8640 & 10,293 & 64,939 & 10,560 & 9824 & 52,926 & 0.029 \\
\hline Sitting & 2558 & 1310 & 7590 & 2230 & 1183 & 6590 & 0.047 \\
\hline PA: physical activity; SD: standard deviation. & & & & &
\end{tabular}

Regarding the four areas of PA, in the first measurement the respondents showed the highest share of activity related to housework, cleaning, and family care (3023 MET$\mathrm{min}$ /week). The reduction of restrictions resulted in students achieving the highest values of metabolic rate in the category of professional work (3273 MET-min/week). The difference in time spent sitting at home, at work, in vehicles, and other places for 7 days, as well as sitting and lying while watching TV, was statistically significant $(p<0.047)$ (Figure 1). 


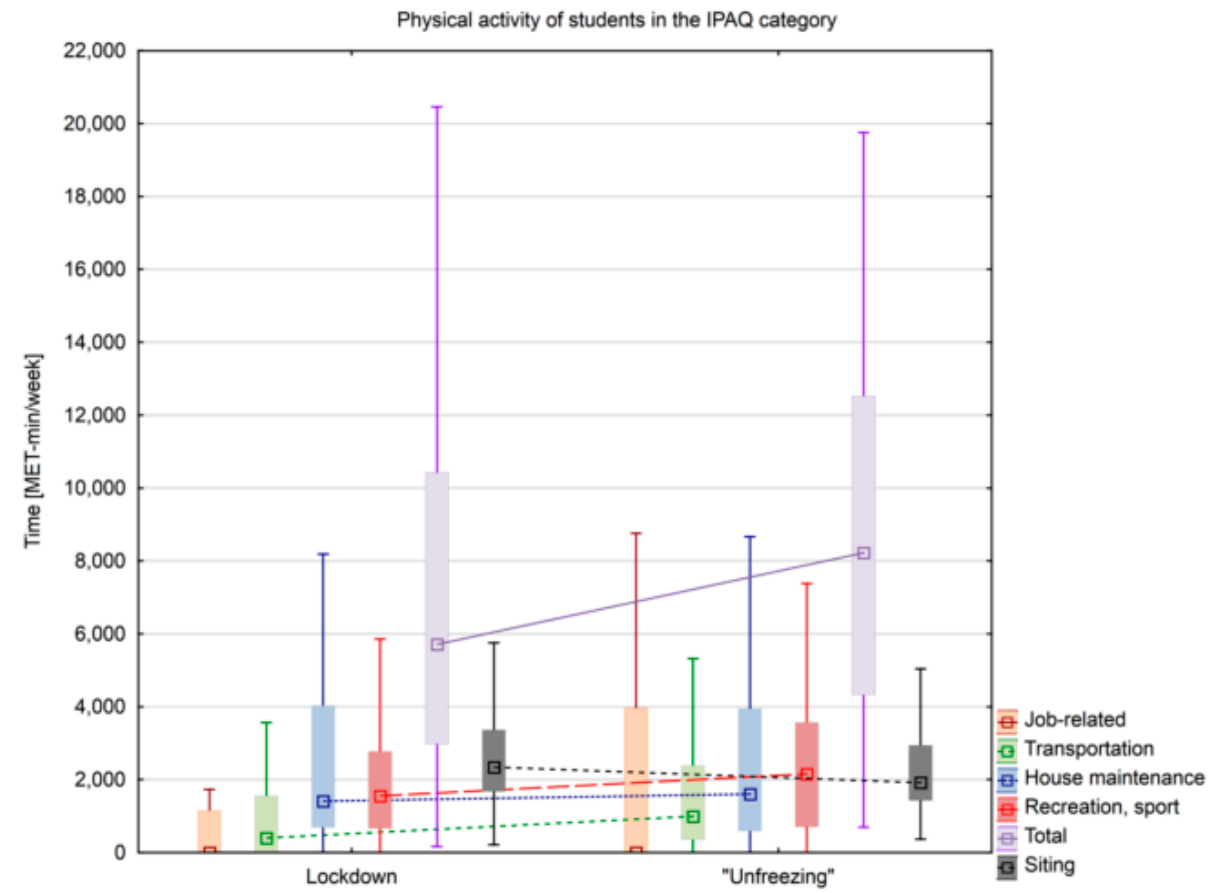

Figure 1. Results of the analysis of physical activity in the two examined time periods.

The comparative analysis of the proportions of the different intensity of PA showed a significant difference (Figure 2). The analysis of total moderate PA showed that during the highest restrictions it averaged 4391 MET-min/week, while during the post-lockdown stage of sport and recreation, it averaged $5037 \mathrm{MET}-\mathrm{min} /$ week. These changes were not statistically significant $(p<0.20)$. The analysis of intensive PA also showed no statistically significant differences $(p<0.14)$. Conversely, a statistically significant difference between the time spent on walking was observed $(p<0.02)$.

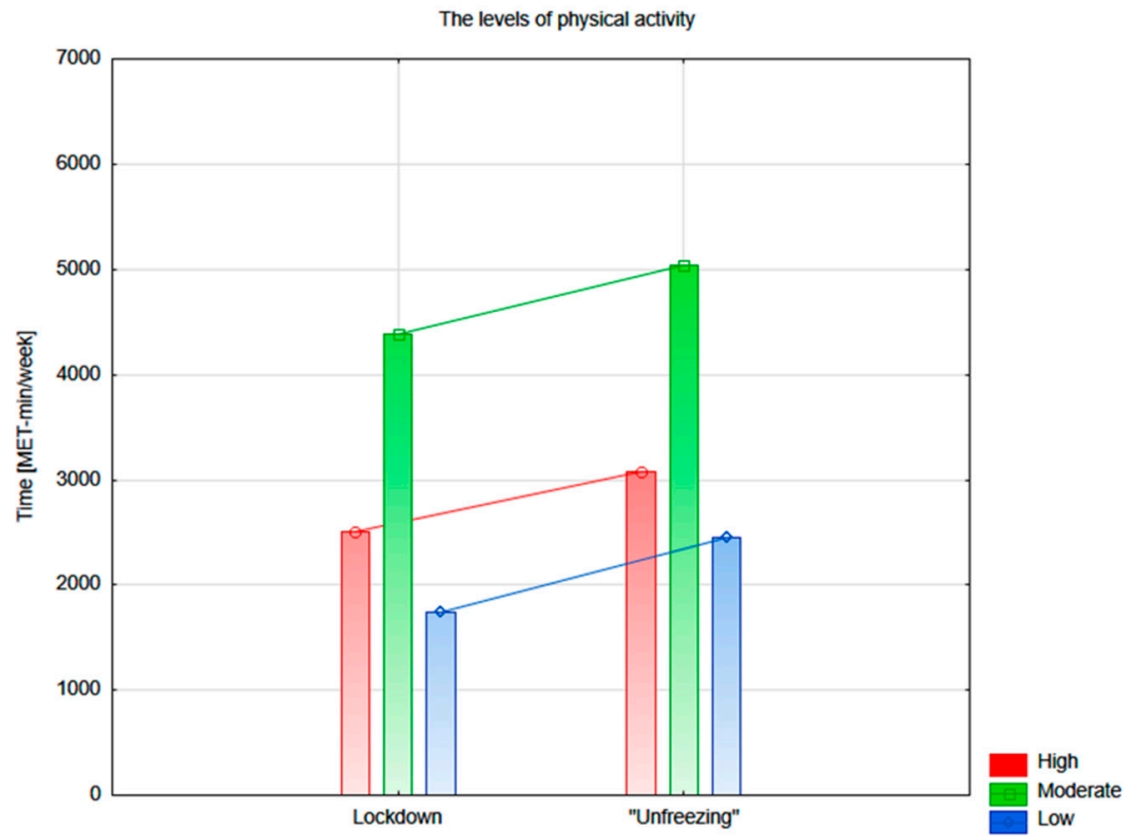

Figure 2. Physical activity of students in the International Physical Activity Questionnaire (IPAQ) category. 
As shown in Figure 2, the majority of students maintained a high level of PA during the highest prohibitions and unfreezing restrictions. It is worth noting that the number of people showing high PA has increased.

\subsection{Correlation Analysis}

The correlation between the level of PA and sociodemographic features such as body mass index (BMI), sex, residence, age, and employment was also assessed. The analysis of correlation between employment revealed statistically significant positive low correlation with total PA $(r=0.32)$, and the first (professional work, $r=0.45)$ and second (time of traveling, $r=0.16$ ) parts of the IPAQ. A statistically significant very low negative correlation between BMI and time spent sitting $(r=-0.18)$ also were noted. This suggests that overweight individuals spent more time sitting. The assessment of the relationship between place of residence and PA showed statistically significant low negative correlations $(\mathrm{r}=-0.34)$ in the third part (house maintenance) of the IPAQ, total score $(\mathrm{r}=-0.17)$, and sitting time $(r=0.21)$. A statistically significant very low negative correlation between age and the fourth (recreation, $r=-0.15$ ) parts of the IPAQ were noted. We did not notice any statistical significant association between gender and level of PA.

\section{Discussion}

The COVID-19 pandemic is a challenge that health care and society have faced in the 21st century. The sense of human freedom has been disturbed due to restrictions on movement, sport, and recreation. Individual life changed and needed to be quickly adapted to the situation. The lockdown period in Poland and around the world contributed significantly to the reduction of opportunities for PA. This remains an important issue since $\mathrm{PA}$ is one of the determinants of physical and mental health, thereby influencing the quality of life of young people [10]. An inadequate level of PA has a negative impact on the human body by increasing the risk of chronic diseases, including cancer [15]. The assessment of the level of PA in the COVID-19 pandemic is a subject which recently emerged in the literature. Several studies on this subject have been published so far confirming that the restrictions imposed translate into reduced PA [16-19]. There was an important trend of increasing time in a sitting position, caused by a long stay at home. This is particularly relevant for young people, due to the considerable time spent on learning online.

The results of this study showed that restoring "normality" in the form of opening forests and parks resulted in an increase in overall average total activity (10,560 MET-min/week) compared to the time of the highest restrictions (8640 MET-min/week). Thus, increasing the percentage of students with high levels of PA was a significant determinant. The government's restrictions were introduced to limit the mobility of society, and the results show that actions have brought the expected effect. Thus, in view of the medical knowledge and the known impact on health of a lack of adequate exercise, it should be stressed that government actions restricting freedom may affect the health of the population. The study by Srivastav et al. carried out during the COVID-19 pandemic in late March/April on a group of 143 Australian physiotherapy students and physiotherapists also determined the energy expenditure incurred during and before the restrictions. The authors also used the IPAQ questionnaire-a short version. The average total PA during the lockdown was 5390 MET-min-week and before, 8143 MET-min-week. The analysis of the results showed that most time and energy was spent on activities of moderate intensity [17]. The full version of the IPAQ questionnaire used in this study gave the opportunity to obtain detailed values in terms of changes in the characteristics of the total level of PA at the "unfreezing" stage. It also gave an opportunity to separate the expenditure of particular types of activity in various aspects of life and the time spent in a sitting position in leisure time.

Giustino et al. analyzed the level of PA on a group of 802 Sicilians, again using the short IPAQ questionnaire. The median total PA during the lockdown period was 1484 MET-min/week. The authors divided the activity level into high ( $\geq 3000$ MET-min/week), moderate ( $\geq 600$ and $\leq 3000 \mathrm{MET}-\mathrm{min} /$ week) and low (<600 MET-min/week). The analysis of the given criteria 
showed the following result: Twenty-five percent of the study participants represented low activity, $51 \%$ moderate, and $24 \%$ high. Referring to similar criteria in our results, the results differ significantly: One percent of respondents represent low activity, 25\% moderate, and $74 \%$ high. Differences in results could be influenced by the age of the study group. The average age in the Giustino study was 32.27 years and in our study, 23.39 [18]. Our results are also in line with the study by Gallo et al., who compared the level of PA in 2018, 2019, and 2020 during the lockdown among Australian university students. The results showed a significant reduction in the time spent walking during the lockdown compared to 2018 and 2019 [19].

Kumari et al. showed, on the basis of a survey, that a large percentage of the examined persons during the coronavirus admitted that their body weight increased on average by $32.0 \%$, whereas up to $75 \%$ of the respondents confirmed an increase in meal consumption during lockdown [20]. The authors suggest that the involvement in aerobic exercises or homework was similar or slightly increased. This is in line with the results of the present study, which showed a reduction in energy expenditure on housework, cleaning, and family care, influenced by "unfreezing sports and recreation". According to Castañeda-Babarro et al., the percentage of respondents performing intensive activity above $75 \mathrm{~min}$ /week dropped by $10.7 \%$. Furthermore, according to the authors, the number of people undertaking at least $150 \mathrm{~min} /$ week of activity of moderate intensity changed when compared to the time before the pandemic (1.4\%) [21]. The quarantine caused by the coronavirus pandemic has had a negative impact not only on the PA of society. As a consequence of long-term social isolation, there is also an increased risk of mental health deterioration. Balanza-Marinez et al. noted that one third of the respondents reported problems with coping with stress and lack of support [22].

Researchers have been trying to develop guidelines for PA during the COVID-19 pandemic, but currently we can only find some indications without structured and precise protocols [23-25]. Countries should take care of the health of the entire population in this way. This difficult time of the COVID-19 pandemic may bring positive changes in society's habits for long-term PA.

The present study must also acknowledge some limitations. Among the main limitations of our study, it is possible there is bias in the reported PA. But, since our questionnaire asked respondents to indicate the level of PA for two different periods (during and after lockdown), we presume that the internal consistency of the respondents led them to report the same bias. Secondly, the study includes a small group of students. A follow-up assessment could provide additional valuable information on the COVID-19 pandemic consequences for the academic community.

\section{Conclusions}

The establishment of "unfreezing" laws for sport and recreation and the reduction of restrictions have significantly contributed to an increase in the overall level of physical activity. The reduction of restrictions has resulted in a decrease in the average time spent sitting on weekdays and holidays. The issue of the impact of isolation caused by the COVID19 pandemic on the level of physical activity resulted in an important reduction in PA rates as analyzed in five IPAQ physical activity groups. In order to avoid the negative effects of a sedentary lifestyle, it is necessary to promote activity to prevent various diseases. We recommend following the scientific guidelines for undertaking PA (i.e., WHO) during the pandemic or individual consultation with a personal trainer or physiotherapist in order to maintain an appropriate pro-healthy dose of exercise. Moreover, more efforts should be made to create programs for students during eLearning periods to promote a healthy lifestyle, especially engaging in physical activity and reducing sitting time or planning supervised physical activity courses in students' schedules.

Author Contributions: Conceptualization, A.R. and K.K.; methodology, A.R., K.K., S.R.; formal analysis, A.R., K.K., S.R., L.C., P.K.; investigation, A.R. and K.K.; data curation, S.R.; writing-original draft preparation, A.R., K.K., S.R.; writing-review and editing, A.R., K.K., S.R., L.C., P.K., J.S.; 
supervision, J.S.; project administration, K.K. All authors have read and agreed to the published version of the manuscript.

Funding: This research received no external funding.

Institutional Review Board Statement: The study was conducted according to the guidelines of the Declaration of Helsinki.

Informed Consent Statement: Informed consent was obtained from all subjects involved in the study.

Data Availability Statement: The data presented in this study are available on request from the corresponding author.

Acknowledgments: We would like to acknowledge Kris Scarlett for language revision.

Conflicts of Interest: The authors declare no conflict of interest.

\section{References}

1. Ralph, R.; Lew, J.; Zeng, T.; Francis, M.; Xue, B.; Roux, M.; Toloue Ostadgavahi, A.; Rubino, S.; Dawe, N.J.; Al-Ahdal, M.N.; et al. 2019-nCoV (Wuhan virus), a novel Coronavirus: Human-to-human transmission, travel-related cases, and vaccine readiness. J. Infect. Dev. Ctries 2020, 14, 3-17. [CrossRef] [PubMed]

2. Wu, J.T.; Leung, K.; Leung, G.M. Nowcasting and forecasting the potential domestic and international spread of the 2019-nCoV outbreak originating in Wuhan, China: A modelling study. Lancet 2020, 395, 689-697. [CrossRef]

3. Guo, Y.R.; Cao, Q.D.; Hong, Z.S.; Tan, Y.Y.; Chen, S.D.; Jin, H.J.; Tan, K.S.; Wang, D.Y.; Yan, Y. The origin, transmission and clinical therapies on coronavirus disease 2019 (COVID-19) outbreak-An update on the status. Mil. Med. Res. 2020, 7, 11. [CrossRef] [PubMed]

4. $\quad$ Li, Q.; Guan, X.; Wu, P.; Wang, X.; Zhou, L.; Tong, Y.; Ren, R.; Leung, K.S.M.; Lau, E.H.Y.; Wong, J.Y.; et al. Early Transmission Dynamics in Wuhan, China, of Novel Coronavirus-Infected Pneumonia. N. Engl. J. Med. 2020, 382, 1199-1207. [CrossRef] [PubMed]

5. Sobaih, A.E.E.; Hasanein, A.M.; Abu Elnasr, A.E. Responses to COVID-19 in Higher Education: Social Media Usage for Sustaining Formal Academic Communication in Developing Countries. Sustainability 2020, 12, 6520. [CrossRef]

6. Cervi, L.; Pérez Tornero, J.M.; Tejedor, S. The Challenge of Teaching Mobile Journalism through MOOCs: A Case Study. Sustainability 2020, 12, 5307. [CrossRef]

7. Tejedor, S.; Cervi, L.; Pérez-Escoda, A.; Jumbo, F.T. Digital Literacy and Higher Education during COVID-19 Lockdown: Spain, Italy, and Ecuador. Publications 2020, 8, 48. [CrossRef]

8. Nussbaumer-Streit, B.; Mayr, V.; Dobrescu, A.I.; Chapman, A.; Persad, E.; Klerings, I.; Wagner, G.; Siebert, U.; Christof, C.; Zachariah, C.; et al. Quarantine alone or in combination with other public health measures to control COVID-19: A rapid review. Cochrane Database Syst. Rev. 2020, 4, CD013574. [CrossRef]

9. Bowden Davies, K.A.; Pickles, S.; Sprung, V.S.; Kemp, G.J.; Alam, U.; Moore, D.R.; Tahrani, A.A.; Cuthbertson, D.J. Reduced physical activity in young and older adults: Metabolic and musculoskeletal implications. Ther. Adv. Endocrinol. Metab. 2019, 10, 2042018819888824. [CrossRef]

10. Wu, X.Y.; Han, L.H.; Zhang, J.H.; Luo, S.; Hu, J.W.; Sun, K. The influence of physical activity, sedentary behavior on health-related quality of life among the general population of children and adolescents: A systematic review. PLoS ONE 2017, 12, e0187668. [CrossRef]

11. Coe, D.P.; Pivarnik, J.M.; Womack, C.J.; Reeves, M.J.; Malina, R.M. Effect of physical education and activity levels on academic achievement in children. Med. Sci. Sports Exerc. 2006, 38, 1515-1519. [CrossRef] [PubMed]

12. Jeong, H.C.; So, W.Y. Difficulties of Online Physical Education Classes in Middle and High School and an Efficient Operation Plan to Address Them. Int. J. Environ. Res. Public Health 2020, 17, 7279. [CrossRef] [PubMed]

13. Craig, C.L.; Marshall, A.L.; Sjostrom, M.; Bauman, A.E.; Booth, M.L.; Ainsworth, B.E.; Pratt, M.; Ekelund, U.; Yngve, A.; Sallis, J.F.; et al. International physical activity questionnaire: 12-country reliability and validity. Med. Sci. Sports Exerc. 2003, 35, 1381-1395. [CrossRef]

14. Group, T.I. Guidelines for Data Processing and Analysis of the International Physical Activity Questionnaire (IPAQ)—Short and Long Forms. Available online: http:/ / www.ipaq.ki.se (accessed on 5 May 2015).

15. Patel, A.V.; Friedenreich, C.M.; Moore, S.C.; Hayes, S.C.; Silver, J.K.; Campbell, K.L.; Winters-Stone, K.; Gerber, L.H.; George, S.M.; Fulton, J.E.; et al. American College of Sports Medicine Roundtable Report on Physical Activity, Sedentary Behavior, and Cancer Prevention and Control. Med. Sci. Sports Exerc. 2019, 51, 2391-2402. [CrossRef] [PubMed]

16. Chen, P.; Mao, L.; Nassis, G.P.; Harmer, P.; Ainsworth, B.E.; Li, F. Coronavirus disease (COVID-19): The need to maintain regular physical activity while taking precautions. J. Sport Health Sci. 2020, 9, 103-104. [CrossRef]

17. Srivastav, A.K.; Sharma, N.; Samuel, A.J. Impact of Coronavirus disease-19 (COVID-19) lockdown on physical activity and energy expenditure among physiotherapy professionals and students using web-based open E-survey sent through WhatsApp, Facebook and Instagram messengers. Clin. Epidemiol. Glob. Health 2020, 9, 78-84. [CrossRef] 
18. Giustino, V.; Parroco, A.; Gennaro, A.; Musumeci, G.; Palma, A.; Battaglia, G. Physical Activity Levels and Related Energy Expenditure during COVID-19 Quarantine among the Sicilian Active Population: A Cross-Sectional Online Survey Study. Sustainability 2020, 12, 4356. [CrossRef]

19. Gallo, L.; Gallo, T.; Young, S.; Moritz, K.; Akison, L. The impact of isolation measures due to COVID-19 on energy intake and physical activity levels in Australian university students. Nutrients 2020, 12, 1865. [CrossRef]

20. Kumari, A.; Ranjan, P.; Vikram, N.K.; Kaur, D.; Sahu, A.; Dwivedi, S.N.; Baitha, U.; Goel, A. A short questionnaire to assess changes in lifestyle-related behaviour during COVID 19 pandemic. Diabetes Metab. Syndr. 2020, 14, 1697-1701. [CrossRef]

21. Castaneda-Babarro, A.; Arbillaga-Etxarri, A.; Gutierrez-Santamaria, B.; Coca, A. Physical Activity Change during COVID-19 Confinement. Int. J. Environ. Res. Public Health 2020, 17, 6878. [CrossRef]

22. Balanza-Martinez, V.; Kapczinski, F.; de Azevedo Cardoso, T.; Atienza-Carbonell, B.; Rosa, A.R.; Mota, J.C.; De Boni, R.B. The assessment of lifestyle changes during the COVID-19 pandemic using a multidimensional scale. Rev. Psiquiatr. Salud Ment. 2020. [CrossRef] [PubMed]

23. Fuzeki, E.; Groneberg, D.A.; Banzer, W. Physical activity during COVID-19 induced lockdown: Recommendations. J. Occup. Med. Toxicol. 2020, 15, 25. [CrossRef] [PubMed]

24. Dwyer, M.J.; Pasini, M.; De Dominicis, S.; Righi, E. Physical activity: Benefits and challenges during the COVID-19 pandemic. Scand. J. Med. Sci. Sports 2020, 30, 1291-1294. [CrossRef] [PubMed]

25. Jimenez-Pavon, D.; Carbonell-Baeza, A.; Lavie, C.J. Physical exercise as therapy to fight against the mental and physical consequences of COVID-19 quarantine: Special focus in older people. Prog. Cardiovasc. Dis. 2020, 63, 386-388. [CrossRef] 